\title{
Design and Evaluation of a Multi-Epitope Peptide of Human Metapneumovirus
}

\author{
Xiaoyan Lia,b Liru Guo ${ }^{a} \quad$ Mei Kong ${ }^{a} \quad$ Xu Su ${ }^{a}$ Dongjing Yang ${ }^{a} \quad$ Ming Zou $^{a}$ \\ Yinghua Liu ${ }^{a}$ Likun Lu ${ }^{a}$ \\ a Tianjin Centers for Disease Control and Prevention, and ${ }^{\mathrm{b}}$ School of Basic Medicine, Tianjin Medical University, \\ Tianjin, PR China
}

\begin{abstract}
Key Words
Human metapneumovirus - B epitope - Cytotoxic T lymphocyte epitope $\cdot$ T helper epitope $\cdot$ Multi-epitope peptide $\cdot$ Adjuvant
\end{abstract}

\begin{abstract}
Objectives: No licensed vaccines or therapeutic agents for human metapneumovirus (hMPV) infection exist to date. We aimed to construct a multi-epitope peptide (MEP) of hMPV to show promising results for epitope-based vaccine development. Methods: Six independent algorithms were screened to predict B-cell epitopes of hMPV, and three algorithms were used to predict cytotoxic T lymphocyte and T helper (Th) lymphocyte epitopes. Predicted epitopes were assembled in series with the spacers GPGPG and KK introduced, termed MEP. Recombinant mep genes were inserted into $\mathrm{pET} 32 \mathrm{a}(+)$ plasmid and expressed in Escherichia coli strain BL21 (DE3). BALB/c mice were immunized with MEP with different adjuvants. Antibody titer, lymphocyte proliferation, cytotoxic T lymphocyte (CTL) activity and splenocyte cytokines were detected 2 weeks later after the last immunization. Microneutralization assay was used to detect neutralizing antibodies. Results: Six B-cell epitopes, four CTL epitopes and two Th epitopes were screened to construct the mep gene. Expressed MEP induced $>10^{4}$ antibodies in $\mathrm{BALB} / \mathrm{c}$ mice, and produced anti-MEP antibody reacting with
\end{abstract}

hMPV strains specifically as detected in indirect fluorescent assay (the titer was 160). The lymphocyte proliferation index, CTL activity and splenocyte cytokines of the MEP immunization groups were higher than in the control group $(p<0.05)$. Both $\lg G 1$ and $\lg G 2 a$ antibodies could be detected in the different groups, and balanced Th1/Th2 cytokines were secreted by splenocytes in these groups. The mean neutralizing titers of the MEP+CpG ODN, MEP+Alum and MEP+Alum+ CpG ODN groups were 87 (95\% Cl 50-126), 93 (95\% Cl 67121) and 96 (95\% Cl 69-147), respectively. Conclusion: MEP of hMPV elicited both strong humoral immunity and cellmediated immunity in mice. The anti-MEP serum could neutralize hMPV infection in vitro. Joint use of CpG ODN and aluminum hydroxide adjuvants obtained the best immune effects. This study may contribute to hMPV epitope-based vaccine development.

(c) 2016 S. Karger AG, Basel

\section{Introduction}

Acute respiratory tract infections (ARTIs) are significant causes of human mortality and morbidity, and are also the leading cause of morbidity in children under 5

Part of this article is based on a study first reported in Chin J Microbiol Immunol 2015;35:646-652.

\section{KARGER 125}

(c) 2016 S. Karger AG, Base

$0300-5526 / 16 / 0586-0403 \$ 39.50 / 0$

E-Mail karger@karger.com

www.karger.com/int 
years of age worldwide [1]. Human metapneumovirus (hMPV) is a relatively newly described virus. It was first isolated in 2001 and currently appears to be one of the major respiratory viruses affecting children, the elderly [2] and immune-compromised individuals [3]. hMPV is classified as the first human member of the Metapneumovirus genus in the Pneumovirinae subfamily within the Paramyxoviridae family [4]. It is the second most important pathogen for young children following respiratory syncytial virus (RSV). Serologic studies have confirmed that worldwide hMPV circulation has been present for at least 50 years [5]. hPMV is responsible for $5-15 \%$ of pediatric hospitalizations for ARTIs [6] and it can be reinfected throughout an individual's lifetime [7-9]. To date, no effective medicines and licensed vaccines are available [10].

Epitope-based vaccines have emerged as a new kind of vaccine and are attracting increasing attention. The recent development of bioinformatics tools provides the opportunity for epitope-based vaccine research, and many bioinformatic tools are freely available online [1119]. This study aimed to predict the hMPV B- and T-cell epitope using various online epitope prediction software tools, and assemble the putative epitopes together to construct a multi-epitope peptide (mep) gene consisting of both $\mathrm{B}$ and $\mathrm{T}$ epitopes. This would then be expressed in Escherichia coli BL21 (DE3) and the immune response of the recombinant E. coli-expressed MEP peptide evaluated with different adjuvants.

\section{Materials and Methods}

\section{Virus and Cell Lines}

Vero-E6 cells were grown in MEM supplemented with $8 \%$ fetal calf sera, $100 \mathrm{U} / \mathrm{ml}$ penicillin and $0.1 \mathrm{~g} / \mathrm{l}$ streptomycin (all from Gibco, Life Technologies Corp., Carlsbad, Calif., USA). P815, kept in our laboratory, were used as target cells for the cytotoxic T lymphocyte (CTL) assay. Monolayers of Vero-E6 cells were infected with either TJ-hMPV-2 strain (type A) or TJ-hMPV-3 strain (type $\mathrm{B})$,which were isolated in-house with Vero-E6 cells from throat swabs of young children with ARTIs conducted in 2009 in our laboratory [6]. After adsorption for $1 \mathrm{~h}$ at $37^{\circ} \mathrm{C}$, virus growth medium (VGM) containing $2.5 \mu \mathrm{g} / \mathrm{ml}$ TPCK-trypsin was added to the flasks. Fresh VGM was replaced every 3-4 days. The cytopathic effect was observed every day until $75 \sim 100 \%$ of the cells were infected. Virus-infected cells were harvested and prepared as hMPV antigen slides to proceed to indirect fluorescent assay (IFA).

\section{Epitope Prediction}

Three bioinformatics tools - Bepipred (threshold 0.35) [11], Bcepred (threshold 2.38) [12] and LEPS [13] - were used for B-cell epitope prediction from hMPV F protein, which utilized the physiochemical properties of the protein, such as hydrophilicity, flexibility, surface probability, solvent accessibility, polarity, antigenic- ity and turns. Another two tools were also used to predict the $\mathrm{B}$ epitope - ABCpred (threshold 0.51) [14], based on artificial neural networks, and LBTOPE (probability threshold 50\%) [15], based on a larger database using support vector machines. The identification of candidate H-2Kd-binding CTL epitopes from hMPV F, G, $\mathrm{N}, \mathrm{M}, \mathrm{SH}, \mathrm{M} 2-1$ and M2-2 proteins was conducted using two predictive algorithms: NetMHCpan [16] and NetMHC [17]. NetMHCII $[18,19]$ was used to predict H2-IA (MHC-II)-restricted Thelper (Th) epitopes from the same proteins as the CTL epitope prediction. A binding score $>0.426$ was considered as the threshold for CTL or Th epitopes. The hMPV L and P proteins were not mapped for epitopes due to their large sizes. Three published CTL epitopes were also used in this study [20].

\section{Design and Synthesis of the mep Gene}

In order to construct gene coding for the MEP that retained the functions of the epitopes and decreased the interactions among them, we selected a theoretically optimal combination of predicted epitopes using DNAstar software. The mep gene fragment was designed by arranging the predicted epitopes in tandem in the order of B, CTL and Th epitopes. The linkers GPGPG and KK were used to separate the epitopes from each other. The MEP codons were optimized for the E. coli host and synthesized by Invitrogen (Regensburg, Germany).

\section{Molecular Cloning, Expression and Purification of}

Recombinant mep

The mep gene was double-digested with BamHI and HindIII, followed by ligation into the corresponding restriction sites of the pET32a(+) vector (Novagen, Darmstadt, Germany) to yield the recombinant plasmid pET32a(+)-mep. The plasmid was transformed in E. coli strain BL21 (DE3). The recombinant bacteria were grown until the $\mathrm{OD}_{600}$ of the culture reached 0.6 , and protein expression was induced by the addition of isopropyl- $\beta-D-$ thiogalactoside (IPTG) to a final concentration of $1 \mathrm{~mm}$. The expression was optimized by growing the cells at 37 and $30^{\circ} \mathrm{C}$. One milliliter of cell culture was harvested every hour up to $5 \mathrm{~h}$ and centrifuged at $6,000 \mathrm{~g}$ for $20 \mathrm{~min}$ at $4^{\circ} \mathrm{C}$. The cell lysate was sonicated and proceeded with SDS-PAGE as well as supernatant to determine the expressed MEP presenting in the inclusion bodies or in soluble form. The supernatant was purified on an Ni-affinity chromatography column (Ni-NTA His Bind Resin $5 \mathrm{ml}, 1 \times$ column; Novagen). The purification steps were performed according to the manufacturer's instructions. The purified MEP was analyzed by SDS-PAGE and tested by Western blot analysis, as described by Ding et al. [21], and the concentration was tested by Bradford assay.

\section{Immunization of Mice}

Four- to six-week-old female BALB/c mice were purchased from the Academy of Military Medical Sciences animal center and housed in a pathogen-free facility at Tianjin Medical University. All work was carried out in accordance with the ethical guidelines of the Institutional Animal Care and Use Committee at Tianjin Centers for Disease Control and Prevention, China.

Twenty-four BALB/c mice were divided into four groups (6 mice in each group) as follows: MEP $20 \mu \mathrm{g}+\mathrm{CpG}$ ODN $10 \mu \mathrm{g}$; MEP $20 \mu \mathrm{g}+$ Alum $100 \mu \mathrm{l}$; MEP $20 \mu \mathrm{g}+$ CpG ODN $5 \mu \mathrm{g}+$ Alum $100 \mu \mathrm{l}$, and an untreated group. The first three groups were immunized intraperitoneally on weeks 0,2 and 4, respectively, whilst the 
untreated mice were used as controls. Two weeks after immunization, the mice were sacrificed and their sera and spleens were collected for the following tests. Adjuvant Imject Alum was from Thermo Fisher (Pierce, Rockford, Ill., USA) and CpG ODN 1826 (phosphorothioate modified 5'-TCCATGACGTTCCTGACGTT- $3^{\prime}$ ) was synthesized by Invitrogen (Shanghai, China).

Determination of Antibody Titers and Isotypes by ELISA

MEP-specific IgG, IgG1, IgG2a and IgA levels in the serum were determined by ELISA. Ninety-six-well microtiter plates (Costar, USA) were coated with $100 \mu \mathrm{l}$ of $\mathrm{MEP}(2 \mu \mathrm{g} / \mathrm{ml})$ at $4^{\circ} \mathrm{C}$ overnight. After washing and blocking with $10 \%$ fetal bovine serum, serial 10 -fold dilutions $\left(10^{2} \sim 10^{6}\right)$ of antisera were added to the wells and incubated at $37^{\circ} \mathrm{C}$ for $1 \mathrm{~h}$, then HRP-conjugated goat anti-mouse IgG, IgG1, IgG2a and IgA antibodies (Santa Cruz Biotechnology, Santa Cruz, Calif., USA) were added subsequently. After incubation at $37^{\circ} \mathrm{C}$ for $1 \mathrm{~h}$, TMB substrate (Thermo Scientific, Waltham, Mass., USA) was used to develop color. A 2-mol/ $1 \mathrm{H}_{2} \mathrm{SO}_{4}$ preparation was used as the stop solution. Antibody titers were assessed as the reciprocal of the highest dilution of sera producing an $\mathrm{OD}_{450} / \mathrm{OD}_{630} \mathrm{~nm}$ ratio value of 2.1 to that of the preimmunized mice sera.

\section{Indirect Immunofluorescent Assay}

Vero-E6 cells were infected with hMPV virus which was isolated at our laboratory [6]. Every day the cytopathic effect was observed until up to $75 \sim 100 \%$ of the cells were infected. The cells were harvested and centrifuged at 2,000 $\mathrm{g}$ for $10 \mathrm{~min}$. After washing 3 times with phosphate-buffered saline (PBS), the cells were transferred onto a slide and fixed with acetone. The slide was covered with 2 -fold diluted anti-MEP serum at $37^{\circ} \mathrm{C}$ for $1 \mathrm{~h}$, FITCconjugated goat anti-mouse IgG was subsequently added and incubated at $37^{\circ} \mathrm{C}$ for $1 \mathrm{~h}$. Fluorescence was observed after sealing the slide. IFA antibody titer was assessed as the reciprocal of the highest dilution of sera producing specific fluorescence.

\section{Lymphocyte Proliferation Assay}

Two weeks after the last immunization, mice were sacrificed and the spleens were aseptically removed. Splenocytes were separated and washed twice with fresh culture medium (RPMI 1640). Lysis buffer $(0.1 \%$ ammonium chloride) was added to the pellet to remove the red blood cells and the cells were counted. The singlecell suspension was cultured in triplicate in 96-well plates at $5 \times 10^{5}$ cells/well in RPMI 1640 medium (Sigma, St. Louis, Mo., USA). The cells were then stimulated in vitro with $50 \mu \mathrm{g} / \mathrm{ml}$ MEP. Cells with medium alone were used as unstimulated controls. The cells were incubated at $37^{\circ} \mathrm{C}$ for $72 \mathrm{~h}$, and $20 \mu \mathrm{l}$ of MTS working solution (Promega, Madison, Wis., USA) containing $2 \mathrm{mg} / \mathrm{ml}$ MTS and $0.92 \mathrm{mg} / \mathrm{ml}$ PMS was added to each well. After incubation at $37^{\circ} \mathrm{C}$ for $2 \mathrm{~h}$, the $\mathrm{OD}_{490 \mathrm{~nm}}$ was read. The stimulation index was calculated as: $\mathrm{OD}_{490 \mathrm{~nm}}$ of the stimulated group/OD $490 \mathrm{~nm}$ of the control group. All cultures were taken in triplicate and the results expressed as the mean stimulation index \pm SD. The confidence intervals were also calculated.

\section{CTL Assay}

The CTL assay was performed as described previously [22]. Briefly, $5 \times 10^{5}$ splenocytes per well in RPMI 1640 medium with $10 \%$ fetal calf serum were used as effector cells, and $2 \times 10^{4} \mathrm{P} 815$ cells were used as target cells (the ratio of effector cells to target cells was 25:1). The target cells were distributed into triplicate wells of a 96-well plate. The effector and target cells were mixed and incubated at $37^{\circ} \mathrm{C}$ for $4 \mathrm{~h}$ before the supernatant was collected. Lactate dehydrogenase activity released into the culture medium was measured with a cytotoxicity assay kit (Promega) according to the manufacturer's instructions.

\section{Cytokine Secretion by Splenocytes}

The splenocytes were incubated in RPMI 1640 medium with $10 \%$ fetal calf serum. MEP protein was added at a final concentration of $50 \mu \mathrm{g} / \mathrm{ml}$. After incubation for $72 \mathrm{~h}$, the splenocyte culture supernatants were collected for cytokine detection. Eight cytokines, IL-2, IL-12, IFN- $\gamma$ (Th1 type), IL-4, IL-5, IL-10 (Th2 type), TNF- $\alpha$ and GM-CSF, in supernatant from the splenocytes cultured from vaccinated mice and control mice were examined using a liquid chip assay (Bio-Plex Pro ${ }^{\mathrm{TM}}$ Mouse Cytokine Th1/Th2 Assay; Bio-Rad, Hercules, Calif., USA).

\section{Microneutralization Assay}

Serum virus-neutralizing antibody titers were determined by a microneutralization assay as described elsewhere, with slight modifications [23]. Briefly, the sera were incubated at $56^{\circ} \mathrm{C}$ for $30 \mathrm{~min}$ to inactivate nonspecific inhibitors. Positive-control wells without serum and negative-control wells without virus or serum were included in triplicate in each plate. Two-fold dilutions of serum were performed in VGM, and then mixed with an equal volume of infection medium containing 50 PFU of TJ-hMPV-2 strains. The antibody-virus mixtures were incubated at $37^{\circ} \mathrm{C}$ for $2 \mathrm{~h}$ and then transferred onto 24 -well plates containing Vero-E6 cells. Following incubation for $3 \mathrm{~h}$, the mixtures were removed and $200 \mu \mathrm{l}$ of fresh VGM (supplemented with $0.75 \%$ hydroxymethyl cellulose, 2 -fold dilutions of sera, as well as $2.5 \mu \mathrm{g} / \mathrm{ml}$ TPCK-treated trypsin) were added to each well. The plates were incubated at $37^{\circ} \mathrm{C}$. Five days later, the cells were fixed in 10\% formaldehyde in PBS for 15 min at $4^{\circ} \mathrm{C}$, air dried and permeabilized by $0.2 \%$ Triton $\mathrm{X}-100$ in PBS. A monoclonal antibody against hMPV N protein (clone 507, Chemicon) was diluted to 1:500 in PBS containing 5\% fetal calf sera and $0.5 \%$ Tween 20 and added to the cells, followed by incubation at $37^{\circ} \mathrm{C}$ for $2 \mathrm{~h}$. Cells were washed and treated with HRPconjugated goat anti-mouse IgG (1:5,000, Santa Cruz) in PBS with $5 \%$ fetal calf serum and $0.5 \%$ Tween $20(50 \mu \mathrm{l} /$ well $)$ for $2 \mathrm{~h}$ at room temperature. After washing, True Blue peroxidase (KPL, Gaithersburg, Md., USA) was added to each well, followed by incubation at $37^{\circ} \mathrm{C}$ for $30 \mathrm{~min}$. Neutralizing titer was defined as the reciprocal of the dilution of serum that reduced color development by $50 \%$ normalized by that of the positive-control wells.

\section{Statistical Analysis}

One-way ANOVA and independent sample t tests were conducted for statistical analysis using SPSS 18.0 software.

\section{Results}

\section{Predicted B, CTL and Th Epitopes, and the Design and Synthesis of a mep Gene}

We selected a theoretically optimal combination of 6 B epitopes, 4 CTL epitopes and 2 Th epitopes (table 1 ) to 
Fig. 1. The MEP amino acid sequence. Boxes indicate linker sequences.
PSCSGKKGNYGPGPGQLAREEQIENPRQSR GPGPGCQNAGSTVYYPNEKDCETRGDHVGPGPGCNINISTT

NYPCKVSTGRHPGPGPGSKVEGEQHVIKGPGPGYITNQDADTVTIKKSPKAGLLSLGPGPGCYLENIEIIGPG

PGGYIDDNQSIGPGPGNYIKVENNLKKARAVSNMPTSAGQIKGPGPGFPLFQANTPPAVLLD

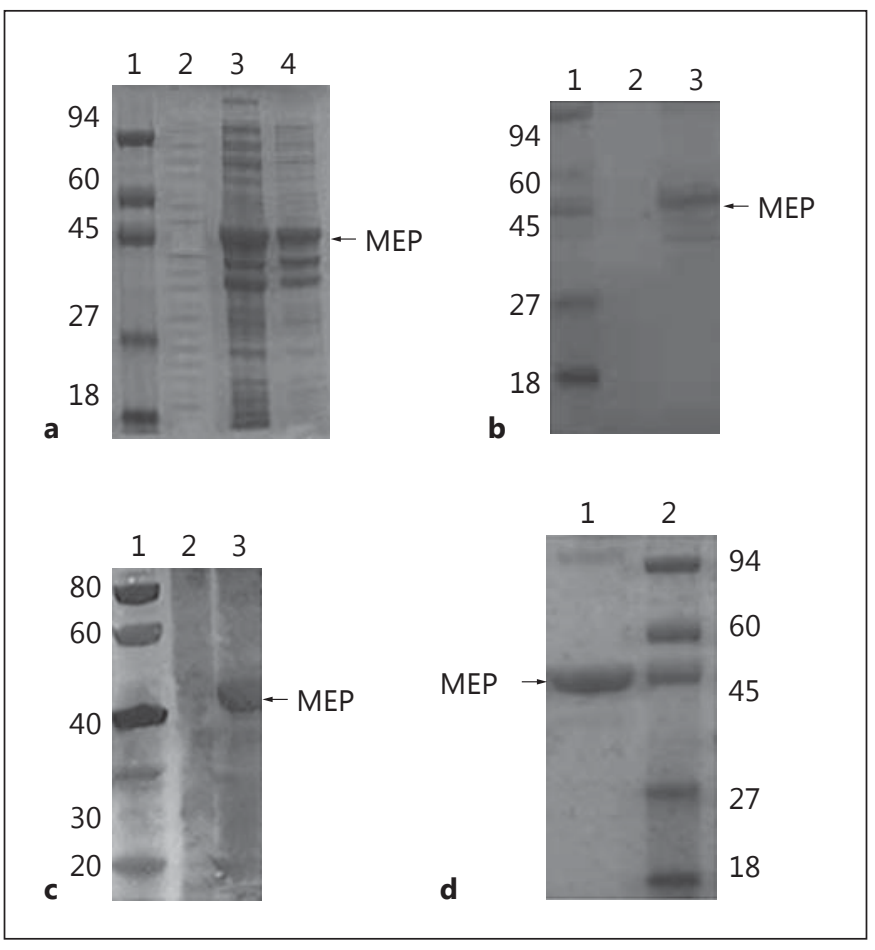

Fig. 2. a SDS-PAGE analysis of MEP expressed in E. coli. Lane 1: protein marker (kDa; Transgene, Beijing, China); lane 2: noninduced pET32a $(+)$; lane 3: supernatant from cell lysis of pET32a $(+)$ mep induced with IPTG; lane 4: pellet from cell lysis of pET32a(+)mep induced with IPTG. b Western blot of purified MEP with anti-His antibody. Lane 1: protein marker ( $\mathrm{kDa}$; Transgene); lane 2: noninduced pET32a(+); lane 3: Western blot of purified MEP. c Western blot of purified MEP with anti-MEP serum. Lane 1: protein marker ( $\mathrm{kDa}$; Transgene); lane 2: noninduced pET32a $(+)$; lane 3: Western blot of purified MEP. d SDS-PAGE analysis of purified MEP. Lane 1: purified MEP; lane 2: protein marker (kDa; Transgene).

design an MEP. The mep gene was designed by arranging the 12 epitopes in tandem in the amino acid sequences, as shown in table 1 . The epitopes were separated from each other by GPGPG or KK. The designed mep codon was optimized as the E. coli host, and the amino acid sequence is shown in figure 1 .
Table 1. Predicted epitopes of hMPV

\begin{tabular}{lllr}
\hline $\begin{array}{l}\text { Epitope } \\
\text { type }\end{array}$ & $\begin{array}{l}\text { Pro- } \\
\text { tein }\end{array}$ & Amino acid sequence & Position \\
\hline B-cell & F & PSCSGKKGNY & $290-299$ \\
epitope & F & QLAREEQIENPRQSR & $88-102$ \\
& F & CQNAGSTVYYPNEKDCETRGDHV & $311-333$ \\
& F & CNINISTTNYPCKVSTGRHP & $350-369$ \\
& F & SKVEGEQHVIK & $428-438$ \\
& F & YITNQDADTVTI & $409-420$ \\
\hline CTL & N & SPKAGLLSL & $307-315^{\text {a }}$ \\
epitope & M2-2 & CYLENIEII & $56-64^{\mathrm{a}}$ \\
& M2-1 & GYIDDNQSI & $81-89^{\mathrm{a}}$ \\
& SH & NYIKVENNL & $51-59$ \\
\hline Th & F & ARAVSNMPTSAGQIK & $228-242$ \\
epitope & M & FPLFQANTPPAVLLD & $36-50$ \\
\hline \multicolumn{2}{c}{ a Published } \\
\hline
\end{tabular}

MEP Protein Expression in E. coli

The MEP protein was highly expressed in E. coli and had the expected size of $40.55 \mathrm{kDa}$, as verified by SDSPAGE after induction with IPTG (fig. 2a). The MEP was expressed in both the inclusion body and soluble form (fig. 2a), and the soluble form was purified by passing the crude preparation through an Ni-affinity chromatography column. The purified MEP had a purity of $95 \%$ and was analyzed by Western blotting (fig. 2b, c).

\section{Anti-MEP Antibody Titers in the Serum of Immunized Mice}

The anti-MEP antibody IgG, IgG1, IgG2a and IgA titers are shown in table 2. All groups elicited potent humoral responses except for the controls. IgG titers were all above $10^{4}$, and both IgG1 and IgG2a were found to be significant. The IgG1 concentration was a little bit higher than that of IgG2a (IgG1/IgG2a was 1.15-1.37). IgA could be detected in the MEP+Alum and MEP+Alum+ CpG ODN groups. 

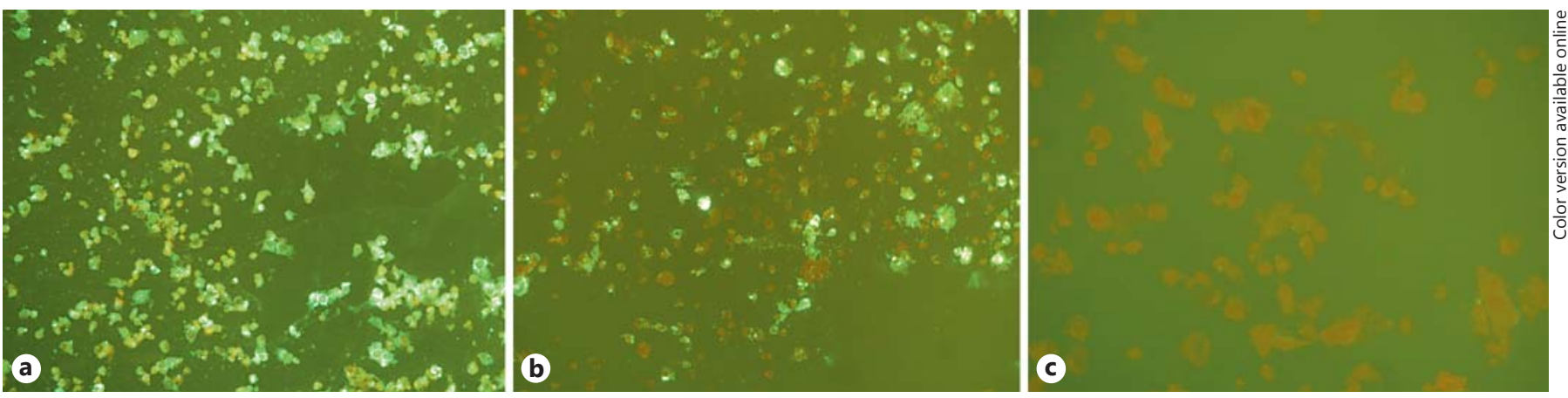

Fig. 3. IFA of the Vero-E6 cells infected with type A hMPV strain (TJ-hMPV-2 stain). a Anti-MEP serum reacted with hMPV strain. b hMPV monoclonal antibody against hMPV N protein (clone 507, Chemicon) reacted with hMPV strain (positive control). c Serum-free PBS reacted with hMPV strain (negative control). Original magnification $\times 200$.

Table 2. Mean titers of anti-MEP antibody in the different groups

\begin{tabular}{lllllc}
\hline Group & IgG & IgG1 & IgG2a & IgG1/IgG2a & IgA \\
\hline MEP+CpG ODN & $1.47 \times 10^{4}$ & $6.8 \times 10^{3}$ & $2.15 \times 10^{3}$ & 1.15 & $<100$ \\
MEP+Alum & $3.17 \times 10^{5}$ & $4.64 \times 10^{5}$ & $1.47 \times 10^{4}$ & 1.37 & 147 \\
MEP+Alum+CpG ODN & $1.48 \times 10^{5}$ & $3.16 \times 10^{5}$ & $4.64 \times 10^{4}$ & 1.18 & $2.15 \times 10^{3}$ \\
\hline
\end{tabular}

\section{Reactivity of Anti-MEP Serum with hMPV Strains}

IFA showed that anti-MEP serum can react with both type A and type B hMPV strains. The mean IFA titers were both 160 (fig. 3).

\section{Lymphocyte Proliferation and CTL Activity Assay}

To evaluate the presence of possible $T$ epitopes recognized in $\mathrm{BALB} / \mathrm{c}$ mice, splenocyte proliferation and CTL activity assays were carried out. Compared with the controls, the MEP+CpG ODN, MEP+Alum and $\mathrm{MEP}+$ Alum+CpG ODN groups showed a significantly $(\mathrm{p}<0.05)$ higher proliferation and higher CTL activity (fig. 4, 5).

\section{Splenocyte Cytokine Secretion}

The cytokine secretions by mice splenocytes are shown in figure 6. The MEP+CpG ODN and $\mathrm{MEP}+$ Alum+CpG ODN groups all showed substantially higher IFN $-\gamma$ secretion (Th1-type; $\mathrm{p}<0.05)$ compared with the controls. In the $\mathrm{MEP}+\mathrm{CpG} \mathrm{ODN}, \mathrm{MEP}+$ Alum and $\mathrm{MEP}+$ Alum $+\mathrm{CpG}$ ODN groups, the secretion of Th2-type cytokines (IL-4, IL-5, IL-10) increased significantly ( $<<0.05)$, with IL-10 in the MEP+Alum+CpG ODN showing the greatest increase. GM-CSF (both Th1/Th2) secretions in the
$\mathrm{MEP}+\mathrm{CpG}$ ODN group increased most significantly $(\mathrm{p}<$ 0.05 ). These results indicated that MEP immunized with different adjuvants could elicit both Th1-type and Th2type immune responses, which influenced the Th1/Th2 response balance.

\section{Microneutralization Assay}

The mean anti-MEP serum neutralization titers of $\mathrm{MEP}+\mathrm{CpG} \mathrm{ODN}, \mathrm{MEP}+$ Alum and $\mathrm{MEP}+$ Alum $+\mathrm{CpG}$ ODN are shown in figure 7 . The results indicated that anti-MEP sera could neutralize hMPV infection in vitro.

\section{Discussion}

hMPV is identical in gene order to the avian pneumovirus (AMPV), which also belongs to the Metapneumovirus genus [4]. As hMPV has a major impact on human health, safe and effective vaccines could decrease the disease burden associated with this new pathogen. Due to the complicated immune mechanism of Paramyxoviridae family viruses, great difficulties have been encountered in hMPV vaccine development. Virus-inactivated vaccines against paramyxoviruses have been shown to 


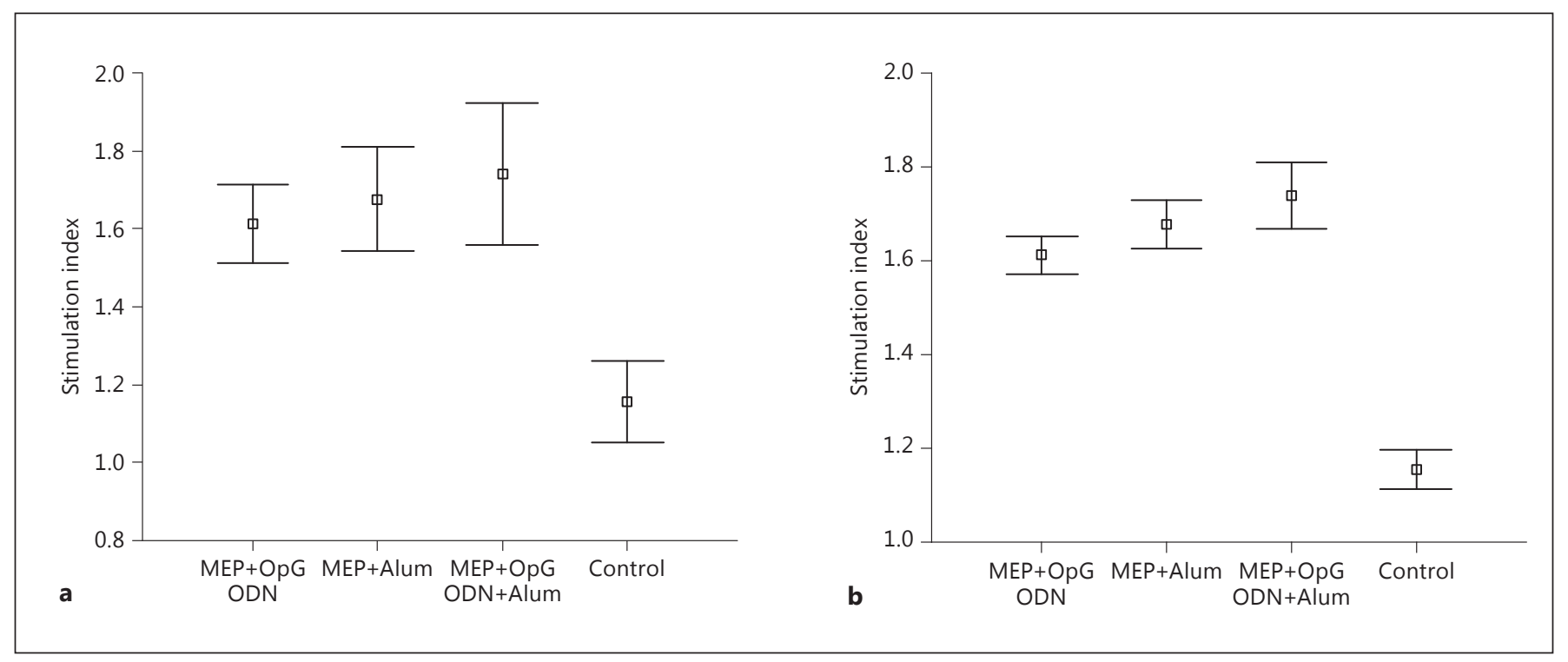

Fig. 4. Lymphocyte proliferation assay in the different groups. The plots indicate $95 \% \mathrm{CI}(\mathbf{a})$ and the mean $\pm \mathrm{SD}(\mathbf{b})$.

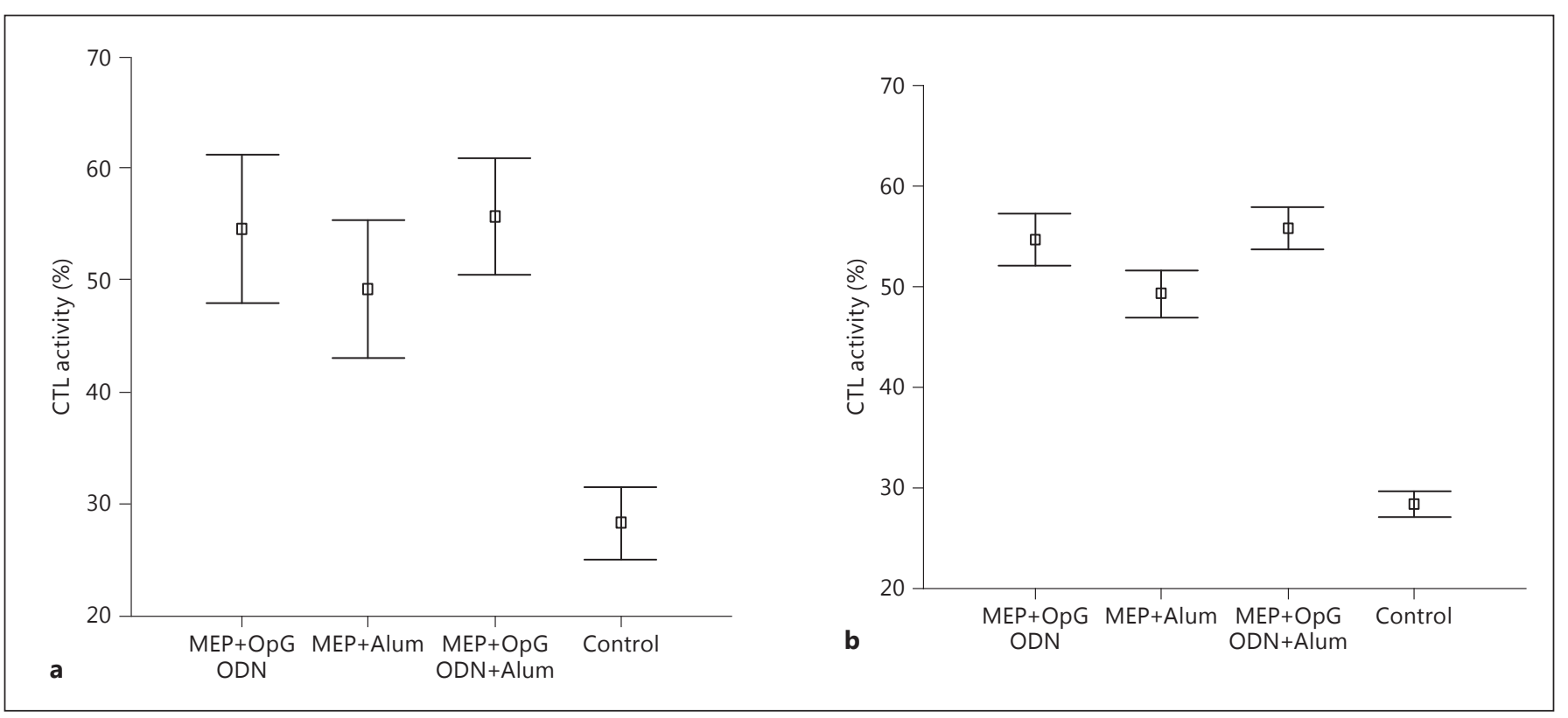

Fig. 5. CTL activity in the different groups. The plots indicate 95\% CI (a) and the mean \pm SD (b).

cause vaccine-enhanced disease upon infection in both humans and animals [24, 25].

An epitope-based vaccine has several advantages in that it is safe, toxic-free, stable, easy to produce and offers the opportunity to engineer the epitopes rationally for potency and breadth. Epitope-based vaccines have been widely reported to show promising results for a range of viral, bacterial and parasitic diseases [26-28]. Recent epitope studies of hMPV have mainly focused on CTL epitopes, which were important to viral clearance. Herd et al. [29] developed a CTL epitope vaccine, and demonstrated that it could elicit CTL- and Th1-type immune responses, 


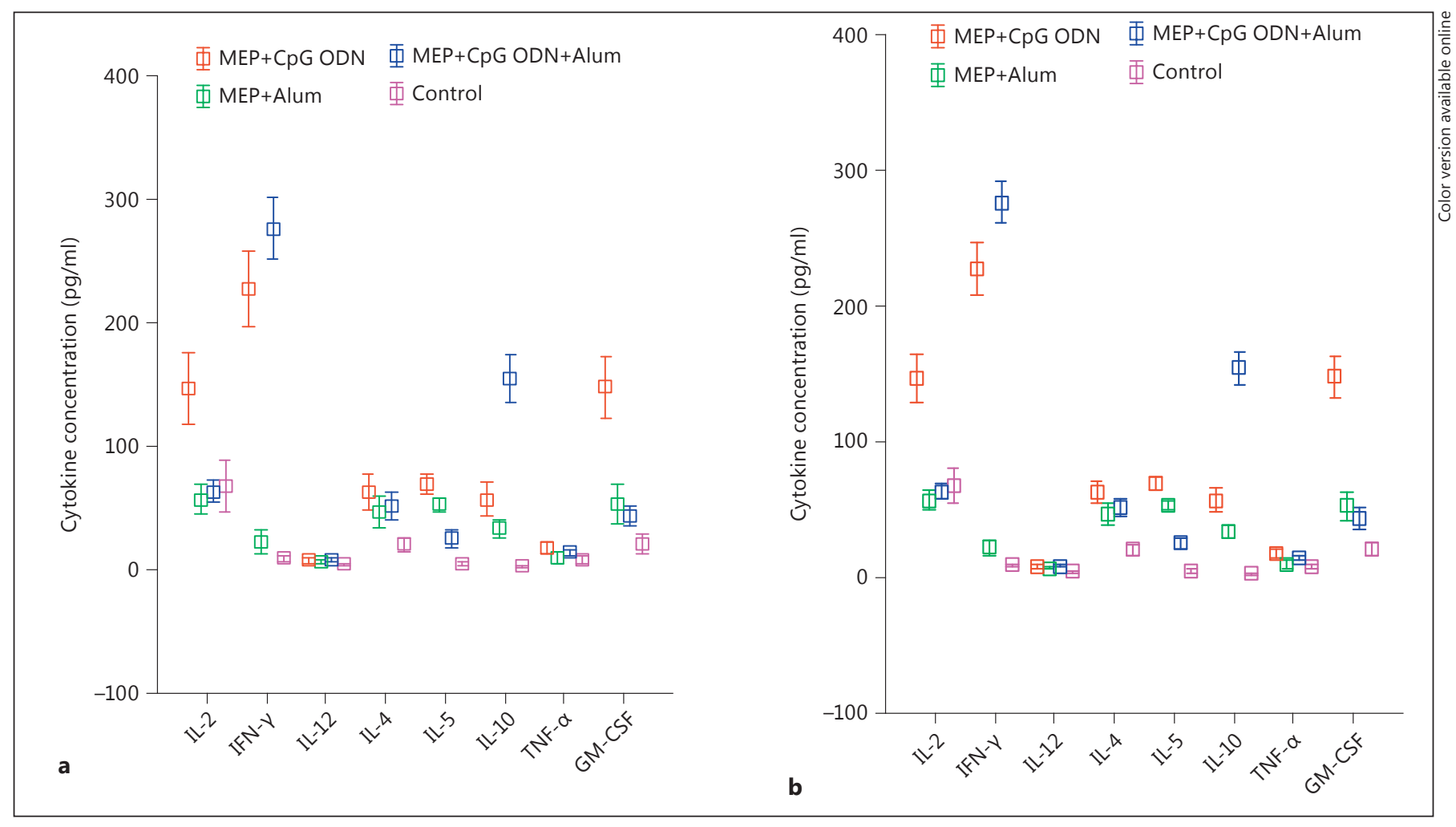

Fig. 6. Cytokine secretion by mice splenocytes. The plots indicate 95\% CI (a) and the mean \pm SD (b).

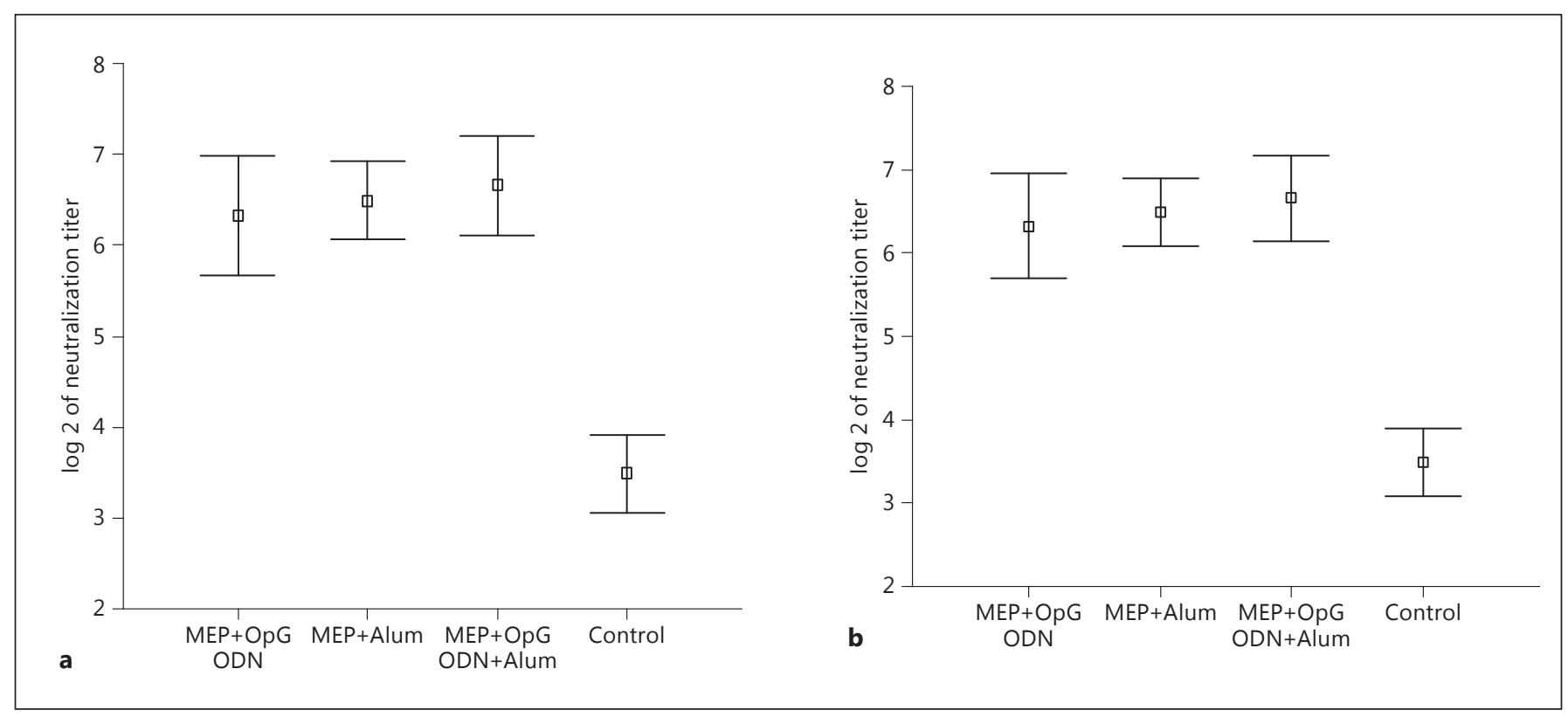

Fig. 7. Serum neutralization antibody titers of the different groups. The plots indicate $95 \%$ CI (a) and the mean \pm SD (b). 
and that the viral titer was decreased significantly in mice lungs. Later the same team predicted 7 human CTL epitopes, 5 of which were conservative in both A- and B-type hMPV [30]. Rock et al. [31] conducted an extensive prediction of hMPV T-cell epitopes and confirmed these epitopes with verification tests.

Although some CTL epitopes have been identified, many other epitopes are still unknown. Traditional epitope identification methods include chemical or biological methods, peptide probe scanning technology, random peptide library and artificial prediction [32]. The disadvantages of the first three methods, such as being cumbersome, necessitating a heavy workload, being time-consuming and having a high cost, limit their application. The development of bioinformatic technology makes epitope prediction possible. Nowadays, many algorithms and software are developed for T- and B-cell epitope prediction, increasing both efficiency and accuracy significantly [11-19]. In this study, we combined several website tools based on different principles to predict $\mathrm{T}$ and $\mathrm{B}$ epitopes in order to increase accuracy as much as possible.

For an ideal humoral and cellular immune response, epitope vaccines should contain both B, CTL and Th epitopes. Th cells activated by a vaccine that contains CD4+ Th epitopes may secrete several CTL-inducing or antiviral cytokines, induce CTL responses and maintain CTL memory [33]. Th epitopes may enhance antibody production against the $\mathrm{B}$ cell determinant [34], and the linking of a Th epitope to a CTL determinant is effective in the generation of antiviral CTLs [35].

The hMPV genome consists of a single negative strand of RNA of approximately $13 \mathrm{~kb}$, containing eight genes that are presumed to encode nine different proteins [5]. Epitopes from the hMPV N and SH proteins were administrated to mice as a peptide vaccine to evaluate the generation of effector and memory cytotoxic lymphocyte and Th1-type cytokine responses, which seem linked to the protection against viral disease [29]. As it is too large (about 2,000 aa), the L protein of hMPV is not suitable for epitope prediction, and without any CTL epitopes in the $P$ protein of human RSV for reference, we selected N, M, F, M2-1, M2-2, SH and G proteins to predict the CTL and Th epitopes. Four CTL and 2 Th epitopes were selected.

Several groups have demonstrated that the viral fusion (F) protein is the most immunodominant hMPV protein [36], and the F protein is highly conserved among hMPV subgroups, with a $>95 \%$ amino acid similarity between A and B groups and $>97 \%$ similarity within a single group, suggesting that a broadly neutralizing antibody response could be elicited if a shared epitope was targeted [37]. In this study, we focused on the F protein to predict B-cell epitopes. In combination, six software applications predicted the results, and 6 peptides were selected as B-cell epitopes.

Spacer introduction is a simple way to design a tandem MEP. KK is an important proteasome for MHC-II-restricted antigen processing [38], and Livingston et al. [39] designed a universal spacer GPGPG. In this study, 6 Bcell epitopes, 4 CTL epitopes and 2 Th epitopes were predicted and connected in series as an MEP. To our knowledge, our study is the first report of tandem assembling of a B, CTL and Th MEP for hMPV. GPGPG and KK residues were introduced as a spacer between adjacent epitopes, which not only minimized junctional epitopes, but also simultaneously augmented proteasome processing, whilst also increasing the immunogenicity [38]. The designed mep gene was expressed in E. coli. Expressed peptide could stimulate strong and specific antibodies (titer $>10^{4}$ ), and these antibodies could react specifically with hMPV stains (as shown in fig. 3).

Previous research indicated that the Th2 response could lead to an enhanced severity of infection; however, other research using the human RSV G1F/M2 vaccine induced a balanced Th1/Th2 response that could protect mice from virus challenge [40]. IgG1/IgG2a and Th1/Th2 cytokine secretion results showed that the MEP designed in this study induced a balanced Th1/Th2 response, and microneutralization assay also showed that it could neutralize the hMPV strain in vitro.

Adjuvants can be used to guide and modulate the immune response to a more balanced response and an increased production of neutralizing antibodies. Traditional adjuvants include aluminum hydroxide and Freund's adjuvant, amongst others. More and newer adjuvants have recently been reported. Traditional adjuvants can induce side effects at the injection site, and usually elicit Th2-biased responses. CpG ODN is a newly developed adjuvant that can stimulate a strong immune response and promote a Th1-biased response. Preclinical studies have shown that CpG ODN can increase the immune response effect of bacterial, viral and parasitic vaccines [41]. Meanwhile, CpG ODN can induce high-titer IgA in mucosa, which plays an important role in the prevention and control of viral respiratory infection. In this study, we evaluated the effects of CpG ODN and aluminum hydroxide, and found that their joint use obtained the best effects (more IgG and IgA were produced). As the cytokine results showed, aluminum hydroxide induced a Th2-biased response, while CpG ODN elicits both Th1 
and Th2 responses, and the joint use of $\mathrm{CpG}$ ODN and aluminum hydroxide produced the highest concentration of Th1 and Th2 cytokines, and also induced more IgA.

In conclusion, we predicted $6 \mathrm{~B}$ epitopes, 4 CTL epitopes and 2 Th epitopes of hMPV, and developed an MEP that can elicit strong humoral immunity, a CTL response and balanced Th1/Th2 immunity. MEP can also induce neutralizing antibodies in mice. The joint use of $\mathrm{CpG}$ ODN and aluminum hydroxide obtained the best immune effects, and this may lay a foundation for hMPV epitope-based vaccine development.

\section{Acknowledgements}

This study received a grant from the China Postdoctoral Science Foundation Funded Project (2013M541186), Tianjin Science and Technology Commission (15JCYBJC24700) and Tianjin Health and Family Planning Commission (2013KY20).

\section{Disclosure Statement}

No conflicts of interest are declared.

\section{References}

1 Alonso WJ, Laranjeira BJ, Pereira SA, Florencio CM, Moreno EC, Miller MA, et al: Comparative dynamics, morbidity and mortality burden of pediatric viral respiratory infections in an equatorial city. Pediatr Infect Dis J 2012;31:e9-e14.

2 Boivin G, Abed Y, Pelletier G, Ruel L, Moisan $D$, Côté S, et al: Virological features and clinical manifestations associated with human metapneumovirus: a new paramyxovirus responsible for acute respiratory-tract infections in all age groups. J Infect Dis 2002;186: 1330-1334.

3 Pelletier G, Dery P, Abed Y, Boivin G: Respiratory tract reinfections by the new human metapneumovirus in an immunocompromised child. Emerg Infect Dis 2002;8:976978.

4 Biacchesi S, Skiadopoulos $\mathrm{MH}$, Boivin G, Hanson CT, Murphy BR, Collins PL, et al: Genetic diversity between human metapneumovirus subgroups. Virology 2003;315:1-9.

5 van den Hoogen BG, de Jong JC, Groen J, Kuiken T, de Groot R, Fouchier RA, et al: A newly discovered human pneumovirus isolated from young children with respiratory tract disease. Nat Med 2001;7:719-724.

6 Li XY, Chen JY, Kong M, Su X, Yi YP, Zou M, et al: Prevalence of human metapneumovirus in hospitalized children with respiratory tract infections in Tianjin, China. Arch Virol 2009; 154:1831-1836.

7 van den Hoogen BG, Herfst S, de Graaf M, Sprong L, van Lavieren R, van Amerongen G, et al: Experimental infection of macaques with human metapneumovirus induces transient protective immunity. J Gen Virol 2007; 88:1251-1259.

8 Walsh EE, Peterson DR, Falsey AR: Human metapneumovirus infections in adults: another piece of the puzzle. Arch Intern Med 2008; 168:2489-2496.
9 Pavlin JA, Hickey AC, Ulbrandt N, Chan YP, Endy TP, Boukhvalova MS, et al: Human metapneumovirus reinfection among children in Thailand determined by ELISA using purified soluble fusion protein. J Infect Dis 2008; 198:836-842.

10 Haas LE, Thijsen SF, van Elden L, Heemstra KA: Human metapneumovirus in adults. Viruses 2013;5:87-110.

11 Larsen JE, Lund O, Nielsen M: Improved method for predicting linear B-cell epitopes. Immunome Res 2006;2:2.

12 Saha S, Raghava GP: BcePred: prediction of continuous B-cell epitopes in antigenic sequences using physico-chemical properties; in Nicosia G, Cutello V, Bentley PJ and Timis J (eds): Artificial Immune Systems, Third International Conference (ICARIS 2004), LNCS 3239. Berlin, Springer, 2004, pp 197-204.

13 Wang HW, Lin YC, Pai TW, Chang HT: Prediction of B-cell linear epitopes with a combination of support vector machine classification and amino acid propensity identification. J Biomed Biotechnol 2011;2011:432830.

14 Saha S, Raghava GP: Prediction of continuous B-cell epitopes in an antigen using recurrent neural network. Proteins 2006;65:40-48.

15 Singh H, Ansari HR, Raghava GP: Improved method for linear B-cell epitope prediction using antigen's primary sequence. PLoS One 2013;8:e62216.

16 Hoof I, Peters B, Sidney J, Pedersen LE, Sette A, Lund O, et al: NetMHCpan, a method for MHC class I binding prediction beyond humans. Immunogenetics 2009;61:1-13.

17 Lundegaard C, Lamberth K, Harndahl M, Buus S, Lund O, Nielsen M: NetMHC-3.0: accurate web accessible predictions of human, mouse and monkey MHC class I affinities for peptides of length 8-11. Nucleic Acids Res 2008;36:W509-W512.

18 Nielsen $\mathrm{M}$, Lund O: NN-align: an artificial neural network-based alignment algorithm for MHC class II peptide binding prediction. BMC Bioinformatics 2009;10:296.
19 Nielsen M, Lundegaard C, Lund O: Prediction of MHC class II binding affinity using SMM-align, a novel stabilization matrix alignment method. BMC Bioinformatics 2007;8:238.

20 Melendi GA, Zavala F, Buchholz UJ, Boivin G, Collins PL, Kleeberger SR, et al: Mapping and characterization of the primary and anamnestic $\mathrm{H}-2^{\mathrm{d}}$-restricted cytotoxic T-lymphocyte response in mice against human metapneumovirus. J Virol 2007;81:1146111467.

21 Ding J, Lu Y, Chen Y: Candidate multi-epitope vaccines in aluminium adjuvant induce high levels of antibodies with predefined multi-epitope specificity against HIV-1. FEMS Immunol Med Microbiol 2000;29: 123-127.

22 Hong W, Xiao S, Zhou R, Fang L, He Q, Wu $\mathrm{B}$, et al: Protection induced by intramuscular immunization with DNA vaccines of pseudorabies in mice, rabbits and piglets. Vaccine 2002;20:1205-1214.

23 Falsey AR, Formica MA, Walsh EE: Microneutralization assay for the measurement of neutralizing antibodies to human metapneumovirus. J Clin Virol 2009;46:314-317.

24 Feuillet F, Lina B, Rosa-Calatrava M, Boivin G: Ten years of human metapneumovirus research. J Clin Virol 2012;53:97-105.

25 Anderson LJ: Respiratory syncytial virus vaccine development. Semin Immunol 2013;25: 160-171.

26 Madhumathi J, Prince PR, Anugraha G, Kiran P, Rao DN, Reddy MV, et al: Identification and characterization of nematode specific protective epitopes of Brugia malayi TRX towards development of synthetic vaccine construct for lymphatic filariasis. Vaccine 2010; 28:5038-5048.

27 Wei JC, Huang YZ, Zhong DK, Kang L, Ishag $\mathrm{H}$, Mao X, et al: Design and evaluation of a multi-epitope peptide against Japanese encephalitis virus infection in $\mathrm{BALB} / \mathrm{c}$ mice. Biochem Biophys Res Commun 2010;396:787-792. 
28 Li S, Peng L, Zhao W, Zhong H, Zhang F, Yan $Z$, et al: Synthetic peptides containing B- and $T$-cell epitope of dengue virus-2 $\mathrm{E}$ domain III provoked B- and T-cell responses. Vaccine 2011;29:3695-3702.

29 Herd KA, Mahalingam S, Mackay IM, Nissen M, Sloots TP, Tindle RW: Cytotoxic T-lymphocyte epitope vaccination protects against human metapneumovirus infection and disease in mice. J Virol 2006;80:2034-2044.

30 Herd KA, Nissen MD, Hopkins PM, Sloots TP, Tindle RW: Major histocompatibility complex class I cytotoxic T lymphocyte immunity to human metapneumovirus (hMPV) in individuals with previous hMPV infection and respiratory disease. J Infect Dis 2008; 197 : 584-592.

31 Rock MT, McKinney BA, Yoder SM, Prudom CE, Wright DW, Crowe JE Jr: Identification of potential human respiratory syncytial virus and metapneumovirus $\mathrm{T}$ cell epitopes using computational prediction and MHC binding assays. J Immunol Methods 2011;374:13-17.

32 Rosa DS, Ribeiro SP, Cunha-Neto E: CD4+ T cell epitope discovery and rational vaccine design. Arch Immunol Ther Exp (Warsz) 2010; 58:121-130.
33 Cardin RD, Brooks JW, Sarawar SR, Doherty PC: Progressive loss of $\mathrm{CD}^{+} \mathrm{T}$ cell-mediated control of a $\gamma$-herpesvirus in the absence of CD4 ${ }^{+}$T cells. J Exp Med 1996;184:863-871.

34 Löwenadler B, Lycke N, Svanholm C, Svennerholm AM, Krook K, Gidlund M: T and B cell responses to chimeric proteins containing heterologous Thelper epitopes inserted at different positions. Mol Immunol 1992;29: 1185-1190.

35 Shirai M, Pendleton CD, Ahlers J, Takeshita T, Newman M, Berzofsky JA: Helper-cytotoxic T lymphocyte (CTL) determinant linkage required for priming of anti-HIV CD8+ CTL in vivo with peptide vaccine constructs. J Immunol 1994;152:549-556.

36 Skiadopoulos MH, Biacchesi S, Buchholz UJ, Amaro-Carambot E, Surman SR, Collins PL, et al: Individual contributions of the human metapneumovirus F, G, and SH surface glycoproteins to the induction of neutralizing antibodies and protective immunity. Virology 2006;345:492-501.
37 Schuster JE, Cox RG, Hastings AK, Boyd KL, Wadia J, Chen Z, et al: A broadly neutralizing human monoclonal antibody exhibits in vivo efficacy against both human metapneumovirus and respiratory syncytial virus. J Infect Dis 2015;211:216-225.

38 Yano A, Onozuka A, Asahi-Ozaki Y, Imai S, Hanada N, Miwa Y, et al: An ingenious design for peptide vaccines. Vaccine 2005;23:23222326.

39 Livingston B, Crimi C, Newman M, Higashimoto Y, Appella E, Sidney J, et al: A rational strategy to design multiepitope immunogens based on multiple Th lymphocyte epitopes. J Immunol 2002;68:5499-5506.

40 Zeng R, Qi X, Gong W, Mei X, Wei L, Ma C, et al: Long-lasting balanced immunity and protective efficacy against respiratory syncytial virus in mice induced by a recombinant protein G1F/M2. Vaccine 2007;25:74227428.

41 Liu L, Wang J, Li B: Research progress of the novel adjuvant CpG ODN (in Chinese). Chin J New Drugs 2014;23:161-170. 